Int. J. Electrochem. Sci., 14 (2019) 10763 - 10774

International Journal of

ELECTROCHEMICAL

SCIENCE

WWW.electrochemsci.org

\title{
Electrochemical Behavior and Corrosion Products of Casing Steel under $\mathrm{CO}_{2}$ Condition
}

\author{
Longting Wang ${ }^{1,2, *}$, Liping Sun ${ }^{2}$, Jichuan Kang ${ }^{2,3}$, Baoping Cai ${ }^{1}$, Yanfu Wang ${ }^{1}$ and Yaonan Wu ${ }^{1}$ \\ ${ }^{1}$ College of Mechanical and Electronic Engineering, China University of Petroleum (East China), \\ Qingdao 266000, China \\ ${ }^{2}$ College of Shipbuilding Engineering, Harbin Engineering University, Harbin 150000, China \\ ${ }^{3}$ Center for Marine Technology and Engineering, University of Lisbon, Portugal \\ *E-mail: wanglt@upc.edu.cn
}

doi: $10.20964 / 2019.12 .24$

Received: 7 July 2019 / Accepted: 8 September 2019 / Published: 29 October 2019

The anodic reaction of $\mathrm{CO}_{2}$ corrosion of steel is closely related to the formation and characteristics of the corrosion product film. However, the relationship between the anodic reaction and the corrosion product film has not been studied. As a useful tool to study the dynamic process of the electrode and the electrode surface state, the measurement technique of AC impedance has been gradually used to study the characteristics of the $\mathrm{CO}_{2}$ corrosion product film along with evaluating corrosion inhibitors and ion adsorption on the electrode surface of casing steel. In this work, the AC impedance characteristics of N80 steel in different media environments were studied using. The influence of the electrode reaction and corrosion product film on the $\mathrm{AC}$ impedance spectrum is analyzed, and a theoretical model of $\mathrm{CO}_{2}$ corrosion is proposed. This model is used to study the influence of temperature and $\mathrm{Cl}^{-}$concentration on the impedance spectrum of the cathode and anode of N80 casing steel, to explore the film formation on the surface of the sample and the electrode reaction process and to understand the impact of environmental factors on $\mathrm{CO}_{2}$ corrosion.

Keywords: Corrosion; Corrosion products; Carbon dioxide; Casing steel; Electrochemical polarization

\section{FULL TEXT}

(C) 2019 The Authors. Published by ESG (www.electrochemsci.org). This article is an open access article distributed under the terms and conditions of the Creative Commons Attribution license (http://creativecommons.org/licenses/by/4.0/). 